\title{
ДОСТАВКА ЭМИТТЕРОВ ЧАСТИЦ С КОРОТКИМ ПРОБЕГОМ В ЯДРА РАКОВЫХ КЛЕТОК С ПОМОЩЬЮ МОДУЛЬНЫХ НАНОТРАНСПОРТЕРОВ
}

\author{
А.С. Соболев ${ }^{1,2}$ \\ ${ }^{1}$ Биологический факультет МГУ имени М.В. Ломоносова, \\ 119234, Россия, Москва, Ленинские горы, 1-12. \\ 2Лаборатория молекулярной генетики внутриклеточного транспорта, \\ Институт биологии гена РАН, 119334, Россия, Москва, ул. Вавилова 34/5.
}

DOI: 10.19163/MedChemRussia2021-2021-115

E-mail: alsobolev@yandex.ru

В докладе дана сравнительная характеристика модульных нанотранспортеров (МНТ) как средств доставки эмиттеров частиц с коротким пробегом (альфа-частиц и электронов Оже) с целью избирательного уничтожения раковых клеток с минимизацией воздействия на окружающие нормальные клетки. Принцип, положенный в основу дизайна МНТ, - использование естественных процессов клеточного транспорта, благодаря чему МНТ, представляющие собой искусственные химерные полипептиды, способны проникать внутрь клеток-мишеней, а затем - в их ядра. На клеточных моделях показано, что доставляемые с помощью МНТ радионуклиды, испускающие электроны Оже $\left({ }^{125}\right.$, $\left.{ }^{111} \ln n^{67} \mathrm{Ga}\right)$ или альфа-частицы $\left({ }^{211} \mathrm{At}\right)$, благодаря специфической доставке в различные раковые клетки-мишени (эпидермоидная карцинома, рак мочевого пузыря, глиобластома, меланома, рак шейки матки), а в них - в ядро, приобретают клеточную специфичность и намного большую эффективность. Помимо МНТ полипептидной природы, разработаны также «гибридные» МHT, полученные путем ковалентного присоединения непептидного лиганда (например, производного фолиевой кислоты) к безлигандному МНТ.

Полученные «гибридные» фолат-МНТ, аналогично МНТ полипептидной природы, специфически интернализовались раковыми клетками-мишенями со сверхэкспрессией фолатных рецепторов, проникали в их ядра и, доставляя радионуклид, эффективно поражали их. МНТ, несущие эмиттерыэлектронов Оже, продемонстрировал выраженную противоопухолевую активность на животных моделях.

Разработанный подход позволяет создавать различные МНТ в зависимости от задачи, например, для создания новых МНТ для новых типов клетокмишеней, нового целевого внутриклеточного компартмента и т.д. Различные варианты применения МНТ для разнообразных целей и задач позволяют рассматривать этот подход как базовый, на основе которого могут быть получены различные частные решения, иными словами, как платформу.

Работа поддержана грантом РНФ № 17-14-01304. 